\title{
Glucose control in home-isolated adults with type 1 diabetes affected by COVID-19 using continuous glucose monitoring
}

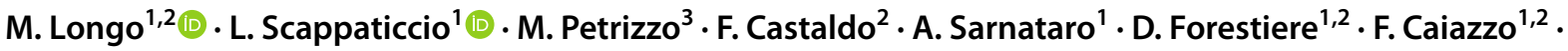

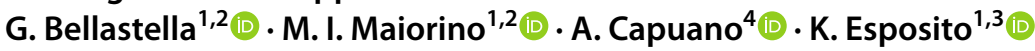

Received: 12 June 2021 / Accepted: 28 August 2021 / Published online: 5 September 2021

(C) The Author(s) 2021

\begin{abstract}
Purpose This study is aimed at evaluating changes in metrics of glucose control in home-isolated patients with type 1 diabetes and COVID-19 using a continuous glucose monitoring (CGM) system.

Methods We included adults aged 18-45 years with type 1 diabetes, using CGM, followed by telemedicine at a Southern Italian University Hospital. Thirty-two home-quarantined subjects with SARS-CoV-2 positive swab constituted the COVID19 group. Thirty age-matched diabetic individuals without COVID-19 formed the control group. The effects of COVID-19 on glycemic control in patients infected were assessed at different time points [2 weeks before-COVID-19 (Time 1), 2 weeks during-COVID-19 (Time 2) and 2 weeks after COVID-19 (Time 3)] and compared with those without infection.

Results A significant reduction of TIR (Time 1 vs Time $2, \%, 60.1 \pm 16.6$ vs $55.4 \pm 19.2, P=0.03$ ), associated with a significant increase of TAR level $2(10.1 \pm 7.3$ vs $16.7 \pm 12.9, P<0.001)$, GMI $(7.1 \pm 0.6$ vs $7.5 \pm 0.8, P<0.001)$, CV $(37.3 \pm 7.1$ vs $39.6 \pm 7.0, P=0.04)$, mean glucose values $(\mathrm{mg} / \mathrm{dL}, 160.2 \pm 26.5$ vs $175.5 \pm 32.6, P=0.001)$ and standard deviation $(59.2 \pm 13.1$ vs $68.6 \pm 17.7, P=0.001)$ was observed in patients with COVID-19. No significant change of glycemic metrics was found in the NO COVID-19 group across the time.

Conclusion Young home-isolated patients with type 1 diabetes and COVID-19 showed a worsening of glucose control during COVID-19, as compared with age-matched diabetic subjects without the infection.
\end{abstract}

Keywords Type 1 diabetes $\cdot$ COVID-19 · Glucose control $\cdot$ CGM $\cdot$ MDI $\cdot$ CSII

M. I. Maiorino

mariaida.maiorino@unicampania.it

1 Department of Advanced Medical and Surgical Sciences, University of Campania “Luigi Vanvitelli”, Piazza Luigi Miraglia 2, 80138 Naples, Italy

2 Division of Endocrinology and Metabolic Diseases, University of Campania “Luigi Vanvitelli", Piazza Luigi Miraglia 2, 80138 Naples, Italy

3 Unit of Diabetes, University of Campania "Luigi Vanvitelli", Naples, Italy

4 Section of Pharmacology "L. Donatelli”, Department of Experimental Medicine, University of Campania "Luigi Vanvitelli", Campania Regional Centre for Pharmacovigilance and Pharmacoepidemiology, Naples, Italy

\section{Introduction}

At the end of 2019, the severe acute respiratory syndrome coronavirus 2 (SARS-CoV-2) started to emerge in China and in most countries all over the word, causing the well-known novel coronavirus disease 2019 (COVID-19) which quickly turned into a declared pandemic. Nearly 145 million cases and more than 3.5 million deaths have been reported worldwide at the end of April 2021 [1].

Much attention has been paid to the different comorbidities involving individuals infected by SARS-CoV-2 [2, 3]. Diabetes is not associated with a higher risk to contract the infection [4, 5], but worsens the prognosis of infected people [6] leading frequently to hospital admission, acute respiratory syndrome and mortality [7, 8]. A recent English whole-population analysis showed that both type 1 and type 2 diabetes were independently associated with a more than two-fold increased risk of in-hospital death with COVID-19 [9]. Moreover, hyperglycemia is associated with increased 
mortality in critically ill patients affected by COVID-19 [10].

Most of evidence relating COVID-19 to diabetes has mainly focused on people with type 2 diabetes with chronic vascular complications [3,11]. Conversely, data on patients with type 1 diabetes and COVID-19 are still very limited and restricted to elderly people in the hospital setting [9]. This may be explained by the lower prevalence of type 1 than type 2 diabetes [12] and the more frequent pauci-symptomatic course of the SARS-CoV-2 infections in individuals affected by type 1 diabetes [13].

Glucose control has a crucial role in the management of diabetes in individuals affected by COVID-19. A recent study of 35 hospitalized individuals affected by COVID-19 with diabetes showed an increased risk of adverse outcomes (admission to the intensive care unit, need for mechanical ventilation, or morbidity with critical illness) in patients with glucose levels $>160 \mathrm{mg} / \mathrm{dL}$ and $<70 \mathrm{mg} / \mathrm{dL}$ and a high glucose variability detected by an intermittently continuous glucose monitoring (iCGM) [14]. On the other hand, in a retrospective study of patients with COVID-19 and pre-existing type 2 diabetes, a well-controlled diabetes with low glycemic variability was associated with reduced medical interventions, major organ injuries, and all-cause mortality [15].

Data on the management of glucose control in patients with type 1 diabetes and concurrent infection by SARSCoV-2 not requiring hospitalization are lacking. This study aims at evaluating the changes in meters of glucose control in a cohort of patients with type 1 diabetes infected by SARS-CoV-2 using a continuous glucose monitoring (CGM) system in the phases preceding, intercurrent and following COVID-19; the same parameters have been assessed in an age-matched cohort of type 1 diabetic subjects without COVID-19 followed by telemedicine visits in the same period.

\section{Research design and methods}

This is a retrospective case-control study of patients with type 1 diabetes followed at Diabetes Unit of the University Hospital "Luigi Vanvitelli" in Naples (Italy). We included in the study people with type 1 diabetes followed by telemedicine who underwent a real-time PCR (RT-PCR) test on nasopharyngeal swab for SARS-CoV-2 between September 2020 and January 2021. Those with a positive result and not requiring hospitalization were included in the case group (COVID-19 group). Age and sex-matched patients with type 1 diabetes and negative test were consecutively enrolled as the control group (NO COVID-19 group). According to the Italian protocol, patients with COVID-19 needed to repeat sequential nasopharyngeal swabs after at least 14 days of self-isolation at home in order to demonstrate the remission of the disease. This was a retrospective case notes analysis study and, as such, the local ethical committee was notified on data collection; however, all patients gave their consent for the use of their personal data for scientific research.

\section{Study participants}

Men and women with type 1 diabetes were included in the study if they attended the Unit of Diabetes at the University Hospital Luigi Vanvitelli (Naples, Italy), were using realtime CGM (Dexcom G6) or iCGM (Free Style, Abbott) in conjunction with intensive insulin therapy (multiple daily insulin injection therapy, MDI, or continuous subcutaneous insulin infusion regimen, CSII) or a hybrid closed loop system (Medtronic 670G) for at least 6 months prior the study with a sensor use $>70 \%$, were sharing data on webbased platform (Carelink, Clarity, Libreview) and were followed by telemedicine between September 2020 and January 2021. Patients would be excluded if they did not agree to be remotely connected to the Diabetes Unit, did not upload the data before the visits, used corticosteroids or high doses of ascorbic acid (vitamin $\mathrm{C}$, dosage $>1000 \mathrm{mg} / \mathrm{dl}$ ) during the infection.

\section{Clinical variables and definition of periods}

Age, sex, duration of diabetes, weight, body mass index (BMI), most recent glycosylated hemoglobin (HbA1c) values, lipid profile, renal function parameters, including creatinine levels and estimated glomerular filtration rate (eGFR), the presence of micro or macrovascular complications and autoimmune diseases were collected for each patient from individual medical records and transferred into an internal medical database. During the visits, a structured questionnaire was proposed to assess the working status, tobacco use, lifestyle habits, physical activity, as well as information about the COVID-19 (times and outcomes for each nasopharyngeal swab for SARS-CoV-2, number of close relatives of patients infected, symptoms developed during the disease and the related-therapy).

Data on glycemic control were remotely extracted during the visits from the above mentioned web-based platforms, with an observation frame for each patient of 2 weeks before the first RT-PCR positive test for SARS-CoV-2 (Time 1, Pre-COVID-19), 2 weeks immediately after the first RTPCR positive test (Time 2, During-COVID-19) and 2 weeks immediately after the first RT-PCR negative test for SARSCoV-2 (Time 3, Post-COVID-19). For each period, all data including CGM-related metrics [mean glucose, standard deviation (SD), coefficient of variation (CV), glucose management indicator (GMI), percentage of time spent in the range of normoglycemia (TIR, 70-180 mg/dL), percentage of time spent below range (TBR, level 1 between 54 and 
$69 \mathrm{mg} / \mathrm{dL}$, level $2<54 \mathrm{mg} / \mathrm{dL}$ ) and percentage of time spent above range (TAR, level 1 between 181 and $250 \mathrm{mg} / \mathrm{dL}$, level 2 between 251 and $400 \mathrm{mg} / \mathrm{dL}$ )] were collected. Our primary endpoint was the change in TIR, TAR level 1 and 2, TBR level 1 and 2, before, during and after the COVID-19.

\section{Statistical analysis}

Descriptive statistics were used to characterize the study sample. The continuous variables are shown as the mean values \pm standard deviation, and the categorical variables are expressed in frequencies and percentages. Repeated measure ANOVA analyses were performed for each variable, with Tukey's test correction, when needed. Statistical significance was accepted at $P<0.05$. All statistical analyses were performed using SPSS software (version 10.05, Chicago, IL, USA).

\section{Results}

Sixty-seven subjects were evaluated for the inclusion in the study. After excluding 5 patients, who assumed corticosteroids, a total of 62 adults with type 1 diabetes have been included, of whom 32 patients with confirmed COVID-19 (COVID-19 group) and 30 patients without COVID-19 (NO COVID-19 group). Mean age of participants in the study was 30.1 years and mean BMI was $25.4 \mathrm{~kg} / \mathrm{m}^{2}$; moreover, mean $\mathrm{HbAlc}$ level was of $7.1 \%$ (54 $\mathrm{mmol} / \mathrm{mol})$ with total daily insulin dose of $42.2 \mathrm{U} /$ day. Fifty-seven percent of patients were females, $43 \%$ were smoking and $55 \%$ were using a CSII system; all participants were using CGM sensor $>70 \%$ of time. Moreover, $46 \%$ of patients were using an iCGM (Free Style, Abbott), 32\% a real-time CGM (rt-CGM) (Dexcom G6) and 22\% a hybrid closed loop system (HCLS) (Medtronic 670G). The clinical characteristics of the two groups are shown in Table 1. There were no significant differences in all the clinical variables evaluated between the two groups. However, at similar level of HbAlc, patients of COVID-19 group showed a worse TIR, TAR and glucose variability related parameters as compared with individuals of NO COVID-19 group. The proportion of patients using CGM (iCGM or rt-CGM) or HCLS was similar in both COVID-19 and NO COVID-19 groups.

More than $50 \%$ of patients contracted the infection by a direct contact (family members, partner, friends); in $44 \%$ of patients the cause of the contagion remained unknown. The infection had an asymptomatic course in $12 \%$ of cases. The reported symptoms included fever (62\%), anosmia and dysgeusia (50\%), body aches (37\%), cold (25\%), dry cough (21\%), nausea and diarrhea (18\%). No patient in the COVID-19 group experienced diabetic ketoacidosis. Mean recovery duration of COVID-19 until the first negative nasopharyngeal swab was 20.8 days (duration range 11-30 days). Azithromycin was the most used drug for COVID-19 (62\%), followed by supplements of vitamins $\mathrm{C}(<1000 \mathrm{mg} / \mathrm{die})$ and $\mathrm{D}(60 \%)$ and paracetamol (22\%).

Table 2 shows changes in the main glucose parameters during the 3 different time points analyzed in the two groups. At Time 2, there was a significant reduction of TIR (Time 1 vs Time $2, \%, 60.1 \pm 16.6$ vs $55.4 \pm 19.2, P=0.03$ ), associated with a significant increase in GMI $(\%, 7.1 \pm 0.6$ vs $7.5 \pm 0.8, P<0.001)$, and CV $(\%, 37.3 \pm 7.1$ vs $39.6 \pm 7.0$, $P=0.04)$ in the COVID-19 group, but not in the NO COVID-19 group. Moreover, a significant increase in TAR level $2(\%, 10.1 \pm 7.3$ vs $16.7 \pm 12.9, P<0.001)$, mean glucose values $(\mathrm{mg} / \mathrm{dL}, 160.2 \pm 26.5$ vs $175.5 \pm 32.6, P=0.001)$ and SD $(\mathrm{mg} / \mathrm{dL}, 59.2 \pm 13.1$ vs $68.6 \pm 17.7, P=0.001)$ were found in the COVID-19 group at Time 2, without significant changes of total insulin doses, which slightly increased only during Time 2. All the metrics, including GMI, mean glucose, SD, CV, TIR and TAR level 2, improved during Time 3 (Post-COVID-19 phase). No significant change of glycemic metrics was observed in the NO COVID-19 group across the different time points considered.

When dividing the COVID-19 group according to the insulin regimen therapy, at Time 2 we found a corresponding significant increase in GMI $(P<0.001)$, mean glucose $(P<0.001), \mathrm{SD}(P=0.001)$, and TAR level $2(P=0.003)$ associated with a reduction of TBR level 2 in patients treated with MDI $(N=15)$ but not in those using CSII $(N=17)$ (Table 3). Participants with CSII did not show any significant change in metrics of glucose control except for a reduction in TAR level $1(P=0.001)$ and TBR level $2(P=0.051)$ at Time 2. Moreover, we observed a worsening of GMI and TAR level 2 in patients with and without fever (Table 4). Furthermore, those with fever showed a significant increase also in mean glucose, SD and total daily insulin dose.

\section{Conclusions}

To the best of our knowledge, this is the first study reporting the changes of the metrics of glucose control during different phases of COVID-19 course in young adults with type 1 diabetes infected by SARS-CoV-2. The main characteristics of this study refer to 1 ) the inclusion of type 1 diabetic people not requiring hospitalization and hence placed in quarantine and 2) the remote monitoring of the patients using a CGM device. The study demonstrated a deterioration of glucose control and glucose variability in this selected population, as demonstrated by the significant increase of GMI, mean glucose, SD and time spent above $250 \mathrm{mg} / \mathrm{dl}$. This trend was more pronounced in patients treated with MDI therapy than those using CSII. Interestingly, the worsening of glucose control was independent of the presence of fever, as patients 
Table 1 Baseline clinical characteristics of patients with type 1 diabetes with and without COVID-19

\begin{tabular}{|c|c|c|c|}
\hline Variables & $\begin{array}{l}\text { COVID-19 } \\
\text { group }(n=32)\end{array}$ & $\begin{array}{l}\text { NO COVID-19 } \\
\text { group }(n=30)\end{array}$ & $P$ \\
\hline Age, years & $32.4 \pm 12.8$ & $27.6 \pm 9.3$ & 0.109 \\
\hline Diabetes duration, years & $13.4 \pm 8.8$ & $12.7 \pm 8.8$ & 0.769 \\
\hline Weight, kg & $73.6 \pm 19.0$ & $71.5 \pm 11.7$ & 0.663 \\
\hline BMI, $\mathrm{kg} / \mathrm{m}^{2}$ & $25.0 \pm 6.4$ & $25.7 \pm 4.2$ & 0.699 \\
\hline Male sex, $n(\%)$ & $13(40)$ & $14(46)$ & 0.658 \\
\hline CSII users, $n(\%)$ & $17(53)$ & $17(56)$ & 0.826 \\
\hline iCGM users, $n(\%)$ & $16(50)$ & $12(40)$ & 0.592 \\
\hline rtCGM users, $n(\%)$ & $9(28)$ & $11(37)$ & 0.655 \\
\hline HCLS users, $n(\%)$ & $7(22)$ & $7(23)$ & 0.868 \\
\hline Smoking, $\%(n)$ & $12(37)$ & $15(50)$ & 0.462 \\
\hline $\mathrm{HbA} 1 \mathrm{c}, \%$ & $7.2 \pm 0.6$ & $6.9 \pm 0.6$ & 0.107 \\
\hline $\mathrm{HbA} 1 \mathrm{c}, \mathrm{mmol} / \mathrm{mol}$ & $55 \pm 17$ & $52 \pm 17$ & 0.490 \\
\hline Fasting plasma glucose, $\mathrm{mg} / \mathrm{dL}$ & $164.3 \pm 25.6$ & $156.4 \pm 22.1$ & 0.200 \\
\hline $\mathrm{SBP}, \mathrm{mmHg}$ & $122.7 \pm 10.3$ & $121.2 \pm 12.4$ & 0.605 \\
\hline $\mathrm{DBP}, \mathrm{mmHg}$ & $73.4 \pm 8.9$ & $70.6 \pm 7.3$ & 0.182 \\
\hline Total cholesterol, mg/dL & $149.8 \pm 22.7$ & $154.2 \pm 28.6$ & 0.566 \\
\hline Cholesterol HDL, mg/dL & $54.2 \pm 7.6$ & $51.8 \pm 8.2$ & 0.336 \\
\hline Cholesterol LDL, mg/dL & $80.2 \pm 15.9$ & $88.7 \pm 18.7$ & 0.172 \\
\hline Triglycerides, mg/dL & $68.3 \pm 20.1$ & $70.2 \pm 19.8$ & 0.709 \\
\hline Creatinine, mg/dL & $0.9 \pm 0.2$ & $0.8 \pm 0.1$ & 0.108 \\
\hline $\mathrm{eGFR}, \mathrm{ml} / \mathrm{min}$ & $100.0 \pm 22.5$ & $109.8 \pm 25.0$ & 0.204 \\
\hline Microvascular complications, $n(\%)$ & $2(6)$ & $1(3)$ & 0.954 \\
\hline Autoimmune diseases, $n(\%)$ & $10(31)$ & $12(40)$ & 0.650 \\
\hline GMI, $\%$ & $7.1 \pm 0.6$ & $7.0 \pm 0.4$ & 0.446 \\
\hline Mean glucose, $\mathrm{mg} / \mathrm{dL}$ & $160.2 \pm 26.5$ & $152.0 \pm 19.9$ & 0.176 \\
\hline $\mathrm{SD}, \mathrm{mg} / \mathrm{dL}$ & $59.2 \pm 13.1$ & $52.1 \pm 9.4$ & 0.018 \\
\hline $\mathrm{CV}, \%$ & $37.3 \pm 7.1$ & $33.9 \pm 5.1$ & 0.035 \\
\hline TIR, \% (70-180 mg/dL) & $60.1 \pm 16.6$ & $70.2 \pm 9.3$ & 0.005 \\
\hline TAR level 1, \% (181-250 mg/dL) & $25.8 \pm 13.0$ & $21.7 \pm 8.2$ & 0.146 \\
\hline TAR level 2, \% (251-400 mg/dL) & $10.1 \pm 7.3$ & $5.4 \pm 4.7$ & 0.004 \\
\hline TBR level 1, \% (54-69 mg/dL) & $3.8 \pm 2.9$ & $3.0 \pm 3.2$ & 0.306 \\
\hline TBR level 2, \% (<54 mg/dL) & $1.2 \pm 2.5$ & $0.8 \pm 1.5$ & 0.452 \\
\hline Total daily insulin dose, U/day & $43.4 \pm 15.5$ & $40.3 \pm 21.9$ & 0.520 \\
\hline
\end{tabular}

Data are expressed as mean and standard deviation (SD)

$B M I$ Body mass index, $C S I I$ continuous subcutaneous insulin infusion, $C V$ coefficient of variation, $D B P$ diastolic blood pressure, $e G F R$ estimated glomerular filtration rate, $G M I$ glucose management indicator, $S B P$ systolic blood pressure, $H D L$ high density lipoprotein, $L D L$ low density lipoprotein, $S D$ standard deviation, TAR time above range, TBR time below range, TIR time in range with and without fever showed an increase of GMI and TAR level 2.

The worse glucose control expressed by lower TIR and higher TAR and glucose variability-indices presented by patients in COVID-19 group at Time 1 may be related to both the incubation and the development of the infection, thus suggesting a potential bidirectional relationship between viral infection and glucose control. Whether poor or suboptimal glycemic control may represent a risk factor for infection for SARS-CoV-2 in patients with diabetes is still unknown; however, hyperglycemia has been extensively associated with the severity and mortality for COVID-19 [10].

There is few evidence reporting the trend of glucose control in people with type 1 diabetes affected by SARS-CoV-2, mostly coming from hospitalized adults affected by multiple comorbidities [16]. The monitoring of glucose levels represents a crucial aspect in patients affected by COVID-19, as a poor glucose control has been associated with worse outcomes in hospitalized patients with both type 1 and type 2 diabetes [16-18]. Moreover, few data on people with diabetes and COVID-19 using CGM are currently available. In 
Table 2 Changes in glycemic metrics in COVID-19 and NO COVID-19 group in different time points

\begin{tabular}{|c|c|c|c|c|c|c|c|c|}
\hline \multirow[t]{2}{*}{ Variables } & \multicolumn{4}{|c|}{ COVID-19 group $(N=32)$} & \multicolumn{4}{|c|}{ NO COVID-19 group $(N=30)$} \\
\hline & $\begin{array}{l}\text { Time } 1 \\
\text { (pre COVID-19) }\end{array}$ & $\begin{array}{l}\text { Time } 2 \\
\text { (during } \\
\text { COVID-19) }\end{array}$ & $\begin{array}{l}\text { Time } 3 \\
\text { (post } \\
\text { COVID-19) }\end{array}$ & $P$ & Time 1 & Time 2 & Time & $P$ \\
\hline GMI, \% & $7.1 \pm 0.6$ & $7.5 \pm 0.8^{*}$ & $7.2 \pm 0.9$ & $<0.001$ & $7.0 \pm 0.4$ & $7.1 \pm 0.5$ & $7.0 \pm 0.3$ & 0.228 \\
\hline Mean glucose, mg/dL & $160.2 \pm 26.5$ & $175.5 \pm 32.6^{*}$ & $168.2 \pm 41.6$ & 0.002 & $152.0 \pm 19.9$ & $153.8 \pm 21.0$ & $150.8 \pm 16.6$ & 0.192 \\
\hline $\mathrm{SD}, \mathrm{mg} / \mathrm{dL}$ & $59.2 \pm 13.1$ & $68.6 \pm 17.7 *$ & $63.2 \pm 20.6$ & $<0.001$ & $52.1 \pm 9.4$ & $54.1 \pm 11.8$ & $53.3 \pm 12.6$ & 0.342 \\
\hline $\mathrm{CV}, \%$ & $37.3 \pm 7.1$ & $39.6 \pm 7.0 *$ & $36.6 \pm 7.5$ & 0.031 & $33.9 \pm 5.1$ & $34.4 \pm 7.1$ & $34.8 \pm 6.8$ & 0.554 \\
\hline TIR, \% (70-180 mg/dL) & $60.1 \pm 16.6$ & $55.4 \pm 19.2 *$ & $59.1 \pm 20.4$ & 0.024 & $70.2 \pm 9.3$ & $69.9 \pm 8.8$ & $71.3 \pm 8.9$ & 0.202 \\
\hline $\begin{array}{l}\text { TAR level 1,\% (181- } \\
250 \mathrm{mg} / \mathrm{dL})\end{array}$ & $25.8 \pm 13.0$ & $24.3 \pm 9.5$ & $22.9 \pm 12.1$ & 0.505 & $21.7 \pm 8.2$ & $22.2 \pm 7.2$ & $20.8 \pm 8.1$ & 0.434 \\
\hline $\begin{array}{l}\text { TAR level 2, \% (251- } \\
400 \mathrm{mg} / \mathrm{dL})\end{array}$ & $10.1 \pm 7.3$ & $16.7 \pm 12.9^{*}$ & $13.6 \pm 10.8$ & $<0.001$ & $5.4 \pm 4.7$ & $5.6 \pm 4.4$ & $5.1 \pm 3.9$ & 0.180 \\
\hline $\begin{array}{l}\text { TBR level 1, \% (54-69 mg/ } \\
\text { dL) }\end{array}$ & $3.8 \pm 2.9$ & $2.7 \pm 2.5$ & $3.0 \pm 2.6$ & 0.071 & $3.0 \pm 3.2$ & $2.7 \pm 3.1$ & $3.0 \pm 4.0$ & 0.856 \\
\hline $\begin{array}{l}\text { TBR level 2, \% (<54 mg/ } \\
\text { dL) }\end{array}$ & $1.2 \pm 2.5$ & $0.8 \pm 1.2$ & $0.7 \pm 1.5$ & 0.165 & $0.8 \pm 1.5$ & $0.7 \pm 1.4$ & $0.5 \pm 1.1$ & 0.157 \\
\hline $\begin{array}{l}\text { Total daily insulin dose, } \\
\text { U/day }\end{array}$ & $43.4 \pm 15.5$ & $52.4 \pm 11.7$ & $47.5 \pm 10.4$ & 0.229 & $40.3 \pm 21.9$ & $40.8 \pm 20.6$ & $40.8 \pm 20.5$ & 0.724 \\
\hline
\end{tabular}

Data are expressed as mean and standard deviation

$C V$ coefficient of variation, GMI glucose management indicator, $S D$ standard deviation, TAR time above range, TIR time in range, TBR time below range

$* P<0.05$ vs Time 1

Table 3 Changes in glucose parameters in patients of COVID-19 group according to insulin regimen therapy

\begin{tabular}{|c|c|c|c|c|c|c|c|c|}
\hline \multirow[t]{2}{*}{ Variables } & \multicolumn{4}{|c|}{ MDI group $(n=15)$} & \multicolumn{4}{|l|}{ CSII group $(n=17)$} \\
\hline & $\begin{array}{l}\text { Time } 1 \\
\text { (pre COVID-19) }\end{array}$ & $\begin{array}{l}\text { Time } 2 \\
\text { (during } \\
\text { COVID-19) }\end{array}$ & $\begin{array}{l}\text { Time } 3 \\
\text { (post } \\
\text { COVID-19) }\end{array}$ & $P$ & $\begin{array}{l}\text { Time } 1 \\
\text { (pre COVID-19) }\end{array}$ & $\begin{array}{l}\text { Time } 2 \\
\text { (during } \\
\text { COVID-19) }\end{array}$ & $\begin{array}{l}\text { Time } 3 \\
\text { (post } \\
\text { COVID-19) }\end{array}$ & $P$ \\
\hline GMI, \% & $6.9 \pm 0.5$ & $7.5 \pm 0.7 *$ & $7.3 \pm 0.8$ & $<0.001$ & $7.2 \pm 0.7$ & $7.5 \pm 0.8$ & $7.3 \pm 0.9$ & 0.143 \\
\hline $\begin{array}{l}\text { Mean glucose, mg/ } \\
\text { dL }\end{array}$ & $152.1 \pm 22.6$ & $176.0 \pm 31.7 *$ & $166.8 \pm 34.9$ & $<0.001$ & $167.3 \pm 28.2$ & $174.9 \pm 34.5$ & $169.6 \pm 49.1$ & 0.450 \\
\hline $\mathrm{SD}, \mathrm{mg} / \mathrm{dL}$ & $56.0 \pm 13.1$ & $72.1 \pm 17.9^{*}$ & $64.6 \pm 19.7$ & 0.001 & $61.9 \pm 12.8$ & $65.5 \pm 17.5$ & $61.8 \pm 22.3$ & 0.269 \\
\hline $\mathrm{CV}, \%$ & $37.6 \pm 9.2$ & $40.9 \pm 7.6$ & $36.9 \pm 8.8$ & 0.076 & $37.1 \pm 5.1$ & $38.4 \pm 6.4$ & $36.3 \pm 6.3$ & 0.383 \\
\hline $\begin{array}{l}\text { TIR, \% (70- } \\
180 \mathrm{mg} / \mathrm{dL})\end{array}$ & $60.1 \pm 18.2$ & $52.6 \pm 20.5$ & $54.3 \pm 18.8$ & 0.061 & $60.1 \pm 16.8$ & $59.2 \pm 19.3$ & $64.7 \pm 21.5$ & 0.324 \\
\hline $\begin{array}{l}\text { TAR level } 1, \% \\
\quad(181-250 \mathrm{mg} / \mathrm{dL})\end{array}$ & $27.1 \pm 16.5$ & $27.9 \pm 9.8$ & $27.2 \pm 13.6$ & 0.862 & $24.6 \pm 9.3$ & $21.0 \pm 8.3^{*}$ & $18.7 \pm 8.8$ & 0.001 \\
\hline $\begin{array}{l}\text { TAR level } 2, \% \\
\quad(251-400 \mathrm{mg} / \mathrm{dL})\end{array}$ & $7.4 \pm 3.4$ & $17.1 \pm 12.8^{*}$ & $14.0 \pm 7.0$ & 0.003 & $12.4 \pm 8.9$ & $16.5 \pm 13.4$ & $13.3 \pm 13.9$ & 0.060 \\
\hline $\begin{array}{l}\text { TBR level 1, \% } \\
(54-69 \mathrm{mg} / \mathrm{dL})\end{array}$ & $4.9 \pm 3.4$ & $3.1 \pm 2.0$ & $3.2 \pm 2.9$ & 0.074 & $2.9 \pm 1.9$ & $2.4 \pm 3.2$ & $2.9 \pm 2.4$ & 0.576 \\
\hline $\begin{array}{r}\text { TBR level 2, \% } \\
(<54 \mathrm{mg} / \mathrm{dL})\end{array}$ & $2.3 \pm 3.4$ & $0.9 \pm 1.4^{*}$ & $0.8 \pm 1.9$ & 0.009 & $0.4 \pm 0.5$ & $0.7 \pm 1.0$ & $0.6 \pm 1.1$ & 0.051 \\
\hline $\begin{array}{l}\text { Total daily insulin } \\
\text { dose, U/day }\end{array}$ & $46.6 \pm 19.6$ & $55.6 \pm 18.5^{*}$ & $44.6 \pm 15.9$ & 0.002 & $40.6 \pm 10.6$ & $49.8 \pm 8.5$ & $48.7 \pm 11.9$ & 0.334 \\
\hline
\end{tabular}

Data are expressed as mean and standard deviation

$C S I I$ continuous subcutaneous insulin infusion, $C V$ coefficient of variation, GMI glucose management indicator, $M D I$ multiple daily insulin injection, $S D$ standard deviation, TAR time above range, TIR time in range, TBR time below range

$* P<0.05$ vs Time 1 
Table 4 Change in glucose parameters in patients of COVID-19 group divided according to the presence or not of fever

\begin{tabular}{|c|c|c|c|c|c|c|c|c|}
\hline \multirow[t]{2}{*}{ Variables } & \multicolumn{4}{|c|}{ Patients with fever $(n=20)$} & \multicolumn{4}{|c|}{ Patients without fever $(n=12)$} \\
\hline & $\begin{array}{l}\text { Time } 1 \\
\text { (pre COVID-19) }\end{array}$ & $\begin{array}{l}\text { Time } 2 \\
\text { (during } \\
\text { COVID-19) }\end{array}$ & $\begin{array}{l}\text { Time } 3 \\
\text { (post } \\
\text { COVID-19) }\end{array}$ & $P$ & $\begin{array}{l}\text { Time } 1 \\
\text { (pre COVID-19) }\end{array}$ & $\begin{array}{l}\text { Time } 2 \\
\text { (during } \\
\text { COVID-19) }\end{array}$ & $\begin{array}{l}\text { Time } 3 \\
\text { (post } \\
\text { COVID-19) }\end{array}$ & $P$ \\
\hline GMI, \% & $7.2 \pm 0.7$ & $7.6 \pm 0.7^{*}$ & $7.2 \pm 0.8$ & 0.001 & $7.0 \pm 0.6$ & $7.4 \pm 0.7 *$ & $7.1 \pm 0.8$ & 0.037 \\
\hline $\begin{array}{l}\text { Mean glucose, mg/ } \\
\text { dL }\end{array}$ & $165.2 \pm 25.9$ & $180.8 \pm 32.5^{*}$ & $168.8 \pm 41.5$ & 0.009 & $156.6 \pm 27.2$ & $168.2 \pm 28.8$ & $163.0 \pm 36.9$ & 0.064 \\
\hline $\mathrm{SD}, \mathrm{mg} / \mathrm{dL}$ & $62.9 \pm 11.8$ & $73.9 \pm 14.9 *$ & $68.8 \pm 18.5$ & 0.009 & $52.4 \pm 12.9$ & $59.2 \pm 16.4$ & $50.2 \pm 15.4$ & 0.051 \\
\hline $\mathrm{CV}, \%$ & $38.9 \pm 7.7$ & $42.0 \pm 6.2$ & $39.7 \pm 5.9$ & 0.060 & $33.9 \pm 3.1$ & $34.7 \pm 4.9$ & $33.2 \pm 9.1$ & 0.760 \\
\hline $\begin{array}{l}\text { TIR, \% (70-180 mg/ } \\
\text { dL) }\end{array}$ & $55.8 \pm 16.4$ & $51.4 \pm 18.5^{*}$ & $58.5 \pm 18.1$ & 0.004 & $66.0 \pm 15.6$ & $61.5 \pm 19.0$ & $64.4 \pm 22.0$ & 0.233 \\
\hline $\begin{array}{l}\text { TAR level 1, \% } \\
(181-250 \mathrm{mg} / \mathrm{dL})\end{array}$ & $28.1 \pm 13.9$ & $24.6 \pm 9.2$ & $22.7 \pm 8.8$ & 0.059 & $22.8 \pm 8.8$ & $25.6 \pm 10.1$ & $21.6 \pm 15.1$ & 0.530 \\
\hline $\begin{array}{l}\text { TAR level } 2, \% \\
\quad(251-400 \mathrm{mg} / \mathrm{dL})\end{array}$ & $11.6 \pm 6.5$ & $19.6 \pm 13.1 *$ & $14.3 \pm 11.3$ & 0.001 & $8.6 \pm 8.8$ & $11.6 \pm 9.7 *$ & $10.0 \pm 9.8$ & 0.006 \\
\hline $\begin{array}{l}\text { TBR level 1, \% } \\
\quad(54-69 \mathrm{mg} / \mathrm{dL})\end{array}$ & $4.3 \pm 3.1$ & $3.4 \pm 3.0$ & $3.6 \pm 2.4$ & 0.216 & $2.3 \pm 1.8$ & $1.1 \pm 0.9$ & $2.2 \pm 2.2$ & 0.300 \\
\hline $\begin{array}{r}\text { TBR level } 2, \% \\
(<54 \mathrm{mg} / \mathrm{dL})\end{array}$ & $1.7 \pm 2.9$ & $1.2 \pm 1.3$ & $1.1 \pm 1.7$ & 0.209 & $0.2 \pm 0.4$ & $0.1 \pm 0.3$ & $0.1 \pm 0.2$ & 0.146 \\
\hline $\begin{array}{l}\text { Total daily insulin } \\
\text { dose, U/day }\end{array}$ & $41.0 \pm 11.7$ & $54.9 \pm 12.9^{*}$ & $49.7 \pm 11.7$ & 0.015 & $43.8 \pm 14.2$ & $48.5 \pm 13.9$ & $46.2 \pm 12.1$ & 0.791 \\
\hline
\end{tabular}

Data are expressed as mean and standard deviation

$C V$ coefficient of variation, GMI glucose management indicator, $S D$ standard deviation, TAR time above range, TIR time in range, TBR time below range

$* P<0.05$ vs Time 1

a retrospective study of 562 individuals with and without diabetes, critically ill patients affected by COVID-19 spent significantly less time in the normal range of glucose levels $(70-150 \mathrm{mg} / \mathrm{dL})$ than non-COVID-19 individuals (44.4\% vs. $68.5 \%$ ), with a higher need of daily insulin dose [19]. Moreover, lower levels of TIR correlated with an increased risk of ventilator requirement and length [19]. In 35 hospitalized patients with diabetes using an iCGM, both TBR (time spent below $70 \mathrm{mg} / \mathrm{dL}$ ) and TAR (time spent above $160-200 \mathrm{mg} / \mathrm{dL}$ ) were significantly associated with composite adverse outcomes and prolonged hospitalization for an average period of 10.2 days [14]. Moreover, in a Chinese pilot study [20], 6 days-CGM data of 13 non-diabetic patients with mild symptoms of COVID-19 were compared with those coming from 3 days-CGM use in a group of 18 healthy age-matched individuals. Patients with COVID-19 had more frequently post-prandial hyperglycemia and higher glucose variability as compared with healthy subjects $(\mathrm{CV}$, $25.6 \%$ vs. $15.7 \%, P<0.001$ ), with significantly lower TIR (time spent in the range of $70-140 \mathrm{mg} / \mathrm{dL}$, median $80.1 \%$ vs. $93.1 \%, P=0.001$ ) and higher TAR (time spent above $140 \mathrm{mg} / \mathrm{dL}$, median $13.9 \%$ vs. $2.3 \%, P=0.006)$ than healthy individuals [20].

Specific viral-induced mechanisms of damage might have contributed to the worsening of glycemic control in our population, as SARS-CoV-2 seems to compromise the hepatic synthesis of glycogen and pancreatic $\beta$-cells insulin delivery [21, 22]. Moreover, the infection is associated with a huge production of cytokines which promotes the onset of stress-related conditions and inflammatory status [22]. All these events may impair glucose homeostasis and further enhance insulin resistance. Finally, selfhome isolation may have worsened daily routine habits and increased physical and psychological stress induced by the infection.

The use of technologies plays a crucial role in diabetes management and is emphasized in the COVID-19 era, as testified by the fair number of studies evaluating worldwide the change of glucose control parameters in patients with type 1 diabetes during the lockdown restrictions. Despite the changes in lifestyle habits and the slowing down of daily routine, a stable or even improved glycemic control was found in patients of all ages with diabetes using a CGM or a hybrid closed loop system during the COVID-19 lockdown [23-25]. In our study, people treated with CSII therapy showed a better control of hyperglycemia and glucose variability than those using MDI therapy, even during viral infection. This finding confirms evidence coming from previous prospective studies which demonstrated that the use of CSII is more effective than MDI therapy in lowering glucose variability, fasting glycemia, and overall hypoglycemic events among young adults with type 1 diabetes [26]. 
Although our patients experienced a worsening of glucose control during COVID-19 phase, a slight restoration of glucose levels was immediately reached in the postCOVID-19 phase. This may coincide with the end of viral infection and the appropriate use of CGM, which helped patients to detect hyperglycemia and prevent further deteriorations of glucose control.

The limitations of the present study include the relative small number of people included, the selection of patients from a single diabetic center and the retrospective design of the study. On the other hand, the use of a valid tool (CGM) to measure metrics of glucose control, the inclusion of a cohort of young patients infected by SARS-CoV-2, the comparison of CGM data before, during and after COVID-19 course and the presence of a healthy control group represent the main strength of this study.

In conclusion, young patients with type 1 diabetes and COVID-19 treated in a home-isolation context showed a worsening of glucose control, as compared with agematched diabetic subjected without infection. Attention should be paid to these young patients in order to prevent adverse health outcomes.

Acknowledgements The authors want to thank all the patients involved in the study.

Author contributions ML and LS conceived the study and wrote the manuscript. MP, FC, AS, DF and FC collected data and contributed to writing the manuscript. GB contributed to the data analysis and reviewed the manuscript for intellectual content. MIM, AC and KE conceived the study, contributed to the data analysis, reviewed and edited the manuscript. All authors approved the final version of the manuscript.

Funding Open access funding provided by Università degli Studi della Campania Luigi Vanvitelli within the CRUI-CARE Agreement. This research did not receive any specific grant from funding agencies in the public, commercial, or not-for-profit sectors.

Data availability All data generated or analysed during this study are included in this published article.

Code availability Not applicable.

\section{Declarations}

Conflict of interest M.I.M has held lectures for Lifescan and Abbott, and received a consultancy fee from Roche. K.E. has held lectures for Roche, Theras, Lifescan and Abbott, and received a consultancy fee from Roche. No other potential conflicts of interest relevant to this article were reported.

Ethical approval This was a retrospective case notes analysis study and, in line with the internal policy, the Ethical Committee of University of Campania Luigi Vanvitelli was notified on data collection.

Consent to participate Not applicable.
Consent for publication Not applicable.

Open Access This article is licensed under a Creative Commons Attribution 4.0 International License, which permits use, sharing, adaptation, distribution and reproduction in any medium or format, as long as you give appropriate credit to the original author(s) and the source, provide a link to the Creative Commons licence, and indicate if changes were made. The images or other third party material in this article are included in the article's Creative Commons licence, unless indicated otherwise in a credit line to the material. If material is not included in the article's Creative Commons licence and your intended use is not permitted by statutory regulation or exceeds the permitted use, you will need to obtain permission directly from the copyright holder. To view a copy of this licence, visit http://creativecommons.org/licenses/by/4.0/.

\section{References}

1. World Health Organization.WHO Coronavirus Disease (COVID-19) Dashboard. https:// covid 19. who. int/. Accessed 11 June 2021

2. Onder G, Rezza G, Brusaferro S (2020) Case-fatality rate and characteristics of patients dying in relation to COVID-19 in Italy. JAMA 323:1775-1776

3. Pal R, Banerjee M (2020) COVID-19 and the endocrine system: exploring the unexplored. J Endocrinol Invest 43:1027-1031

4. Apicella M, Campopiano MC, Mantuano M et al (2020) COVID-19 in people with diabetes: understanding the reasons for worse outcomes. Lancet Diabetes Endocrinol 8:782-792

5. Jia X, Gesualdo P, Geno Rasmussen C (2021) Prevalence of SARS-CoV-2 antibodies in children and adults with type 1 diabetes. Diabetes Technol Ther. https://doi.org/10.1089/dia.2020. 0609

6. Sur J, Sharma J, Sharma D (2021) Diabetes might augment the severity of COVID-19: a current prospects. Front Cardiovasc Med 7:613255

7. Cariou B, Hadjadj S, Wargny M et al (2020) Phenotypic characteristics and prognosis of inpatients with COVID-19 and diabetes: the CORONADO study. Diabetologia 63:1500-1515

8. Ciardullo S, Zerbini F, Perra S et al (2021) Impact of diabetes on COVID-19-related in-hospital mortality: a retrospective study from Northern Italy. J Endocrinol Invest 44:843-850

9. Barron E, Bakhai C, Kar P et al (2020) Associations of type 1 and type 2 diabetes with COVID-19-related mortality in England: a whole-population study. Lancet Diabetes Endocrinol 8:813-822

10. Mazori AY, Bass IR, Chan L et al (2021) Hyperglycemia is associated with increased mortality in critically ill patients with COVID-19. Endocr Pract 27:95-100

11. Filardi T, Morano S (2020) COVID-19: is there a link between the course of infection and pharmacological agents in diabetes? J Endocrinol Invest 43:1053-1060

12. Mobasseri M, Shirmohammadi M, Amiri T et al (2020) Prevalence and incidence of type 1 diabetes in the world: a systematic review and meta-analysis. Health Promot Perspect 10:98-115

13. Cardona-Hernandez R, Cherubini V, Iafusco D et al (2021) Children and youth with diabetes are not at increased risk for hospitalization due to COVID-19. Pediatr Diabetes 22:202-206

14. Shen Y, Fan X, Zhang L et al (2021) Thresholds of glycemia and the outcomes of covid-19 complicated with diabetes: a retrospective exploratory study using continuous glucose monitoring. Diabetes Care 44:976-982 
15. Zhu L, She ZG, Cheng X, Qin JJ et al (2020) Association of blood glucose control and outcomes in patients with COVID-19 and pre-existing type 2 diabetes. Cell Metab 31:1068-1077.e3

16. Holman N, Knighton P, Kar P (2020) Risk factors for COVID19-related mortality in people with type 1 and type 2 diabetes in England: a population-based cohort study. Lancet Diabetes Endocrinol 8:823-833

17. Gregory JM, Slaughter JC, Duffus SH et al (2021) COVID19 severity is tripled in the diabetes community: a prospective analysis of the pandemic's impact in type 1 and type 2 diabetes. Diabetes Care 44:526-532

18. Chen L, Sun W, Liu Y et al (2021) Association of early-phase in-hospital glycemic fluctuation with mortality in adult patients with coronavirus disease 2019. Diabetes Care 44:865-873

19. Kapoor R, Timsina LR, Gupta N et al (2020) Maintaining blood glucose levels in range $(70-150 \mathrm{mg} / \mathrm{dL})$ is difficult in COVID19 compared to non-COVID-19 ICU patients-a retrospective analysis. J Clin Med 9:3635

20. Shen Y, Zhang L, Fan X et al (2021) Glycemic fluctuations caused by COVID-19: results from continuous glucose monitoring. Obes Med 22:100328

21. Chen N, Zhou M, Dong X et al (2020) Epidemiological and clinical characteristics of 99 cases of 2019 novel coronavirus pneumonia in Wuhan, China: a descriptive study. Lancet 395:507-513
22. Ceriello A, De Nigris V, Prattichizzo F (2020) Why is hyperglycaemia worsening COVID-19 and its prognosis? Diabetes Obes Metab 22:1951-1952

23. Bonora BM, Boscari F, Avogaro A et al (2020) Glycaemic control among people with type 1 diabetes during lockdown for the SARS-CoV-2 outbreak in Italy. Diabetes Ther 11:1-11

24. Longo M, Caruso P, Petrizzo M et al (2020) Glycemic control in people with type 1 diabetes using a hybrid closed loop system and followed by telemedicine during the COVID-19 pandemic in Italy. Diabetes Res Clin Pract 169:108440

25. Capaldo B, Annuzzi G, Creanza A et al (2020) Blood glucose control during lockdown for COVID-19: CGM metrics in Italian adults with type 1 diabetes. Diabetes Care 43:e88-e89

26. Maiorino MI, Bellastella G, Casciano O et al (2018) The effects of subcutaneous insulin infusion versus multiple insulin injections on glucose variability in young adults with type 1 diabetes: the 2-year follow-up of the Observational METRO Study. Diabetes Technol Ther 20:117-126

Publisher's Note Springer Nature remains neutral with regard to jurisdictional claims in published maps and institutional affiliations. 